Mario Gaudino ORCID iD: 0000-0003-4680-0815

\title{
Invited Commentary: Is endoscopic radial artery harvesting open for business?
}

\author{
Authors: N. Bryce Robinson $\mathrm{MD}^{1}$, James Tatoulis $\mathrm{MD}^{2}$, Mario Gaudino MD ${ }^{1}$ \\ ${ }^{1}$ Weill Cornell Medicine, Department of Cardiothoracic Surgery, New York, NY, USA \\ ${ }^{2}$ Royal Melbourne Hospital, University of Melbourne, Melbourne, Victoria, Australia \\ Running title: Commentary on radial harvesting
}

Word count: 1946

Conflicts of interest: none

Funding: none

Acknowledgements: none

Keywords: Endoscopic harvesting, Open harvesting, Radial artery, coronary artery disease, Coronary artery bypass grafting

\section{Corresponding author:}

Mario Gaudino, MD

Department of Cardiothoracic Surgery, Weill Cornell Medicine

525 E 68th St, New York, NY 10065

Telephone: +1 2127469440 Fax: +1 2127468080

E-mail: mfg9004@med.cornell.edu

\begin{abstract}
With the resurgence of the radial artery in coronary artery bypass grafting, the debate between the optimal harvesting technique continues. Here we comment on a randomized series in which the authors conclude that endoscopic harvesting techniques offer the benefit of improved cosmetic outcomes and decreased neurological complications with comparable graft-related outcomes when compared with open
\end{abstract}

This is the author manuscript accepted for publication and undergone full peer review but has not been through the copyediting, typesetting, pagination and proofreading process, which may lead to differences between this version and the Version of Record. Please cite this article as doi: 10.1111/jocs.14708.

This article is protected by copyright. All rights reserved. 
harvesting. We conclude that while this study is well designed and conducted, there are several areas of concern including surgical technique and statistical power.

We read with great interest this single-center prospective study by Tamim et. al. comparing endoscopic radial artery harvesting (ERAH) and open radial artery harvesting (ORAH) for coronary artery bypass grafting (CABG). ${ }^{1}$ The authors report a randomized series including 50 total patients ( $n=25$ randomized to both groups). They found no difference in harvest time, length of conduit, wound healing, post-operative complications including major neurologic dysfunction, and graft patency rate at 1 year as determined by CT Angiography (CTA). The only significantly different variables reported between the two groups were incision length, early (defined as in-hospital) minor and major neuralgias, and patient satisfaction with cosmetic appearance, all of which favor the endoscopic harvesting group.

With the introduction of improved harvesting and preservation techniques, the radial artery has seen a renaissance in cardiac surgery. Observational and randomized evidence have shown better long-term patency rates associated with the arterial conduit over the saphenous vein, and centers across the world are now using the radial artery (RA) with increasing frequency. ${ }^{2,3}$ As such, the debate as to the optimal approach for harvesting of the RA during coronary artery bypass grafting is timely and important. Similar to the data reported herein, a number of previously published studies point to improved cosmetics, patient satisfaction, and lower wound complication rates associated with the endoscopic approach, with similar rates of short- and long-term graft patency. ${ }^{4-6}$ The authors are to be commended for embracing a multiple arterial grafting approach to CABG, with $22 \%$ bilateral internal thoracic artery use, with excellent operative and 12 month outcomes and a short length of stay of only seven days. There are, however, a few areas of concern that must be addressed.

First, and most importantly, is the issue of endothelial damage and its potential impact on long-term patency rates. The authors report at 1 year that five patients developed $>50 \%$ stenosis of the RA graft- 3 in the endoscopic group and 2 in the open group. Of note, in all five patients the RA-coronary anastomosis was to a target vessel with less than $90 \%$ stenosis, a known risk factor for graft failure. ${ }^{7}$ Furthermore, 3 of the 5 failed grafts were to the right coronary system, another risk factor for failure. It is difficult to make much of these findings with only one year of follow up, and the authors acknowledge this limitation in their analysis. What the authors fail to discuss, however, is the impact that endoscopic harvesting techniques may have on endothelial function. ERAH occurs in a constricted space, which increases the risk of mechanical injury to the conduit when compared with ORAH. In an comparative analysis published by our group in 2019, ORAH was associated with improved preservation of endothelial function as demonstrated by organ bath functional evaluation. ${ }^{8}$ While future studies are needed to show an association between endothelial damage to the RA and patency rates, there is data showing the adverse impact of endoscopic harvesting on the saphenous vein. ${ }^{9,10}$

This article is protected by copyright. All rights reserved. 
It is also important to note that the foundation of our recommendations relating to the RA are developed from series that used mainly the open approach. The 2016 Society of Thoracic Surgeons Guidelines ${ }^{11}$, for example, based their statement on studies such as the Radial Artery Patency Study, Radial Artery Versus Saphenous Vein Patency, Radial Artery Patency and Clinic Outcomes, none of which used endoscopic radial artery harvesting. ${ }^{12-14} \mathrm{~A}$ few small trials have shown no difference in patency rates between ERAH and ORAH. Bleiziffer and colleagues reported equivalent patency rates at 1 year in a 50 patient analysis. ${ }^{15}$ Similarly, Burns et. al. reported no difference in patency rates at 5 years between radial grafts harvested endoscopically versus open in a post-hoc analysis of a randomized trial that did not use protocol driven angiographic analysis and only included 66 patients (55.5\% of patients in original trial). ${ }^{16}$ It is important to note that the rate of RA failure is known to be quite low, and thus all these series are largely underpowered. Future adequately powered randomized assessment of long-term outcomes is needed before a definitive conclusion about long-term patency and clinical outcomes of ERAH can be made.

Second, while Tamim et al study does report important outcomes that are consistent with those in other published material, it appears to be significantly underpowered. In published series, the rate of any (minor and major) neurologic complication following ORAH ranges from $10 \%$ to $39 \%$, depending on the definition used. ${ }^{17-19}$ Using the highest estimate of neurologic complication rates, a trial with $80 \%$ power to detect a $20 \%$ difference in postoperative morbidity caused by neurological complications wound need to enroll at least 81 patients in each arm. This number becomes even higher when considering the more clinically significant major neurologic complications, an exceedingly uncommon finding following radial artery harvesting in both groups.

Third, the authors report unique technical aspects to their harvesting techniques that would limit the applicability of their outcomes, even if properly powered. In the ORAH arm, the authors performed an incision directly over the course of the RA. Previous series have shown a decreased rates of neurosensory deficits with a more medially directed curvilinear incision, which avoids the superficial radial and lateral cutaneous nerves. During ORAH it is also important that the distal end of the incision is at least $2 \mathrm{~cm}$ above the flexion crease at the wrist in order to avoid the most sensitive areas while preserving small anastomotic branches. ${ }^{20}$ Finally, endoscopic harvesting relies heavily on operator experience. Previous publications have reported significant learning curves, with operators needing between 10 and 20 cases prior to achieving proficiency and timing similar to that seen in ORAH. Thus, ERAH is currently limited to centers with an "expert harvester" available. ${ }^{21,22}$

Finally, the authors do not report using any of the commonly accepted and validated scoring criterion for objectively quantifying arm dysfunction, nor do they describe employing objective measures of grip strength. In fact, the authors do not define how they differentiated between major and minor neuralgias. Prior analyses have used

This article is protected by copyright. All rights reserved. 
comprehensive 100-point questionnaires and measured hand grip using a dynamometer, ${ }^{23}$ nerve conduction studies, ${ }^{24}$ or detailed manual examination. ${ }^{25}$

Tamim and colleagues conclude that, in experienced hands, ERAH can be performed safely and effectively with no difference in short-term graft-related outcomes. One must be cautious in interpreting these findings, however, in the light of this study being underpowered, with inadequately measured and defined outcomes. At our institution, it is routine practice to harvest radial artery using the open technique. While cosmesis is certainly important, excellent long-term graft patency outcomes is more important. Until more conclusive data is available, it would appear that endoscopic harvesting of the radial artery is not yet open for business.

\section{References:}

1. Tamim M, Alexiou C, Al-Hassan D, Al-Faraidy K. Prospective randomized trial of endoscopic vs open radial artery harvest for CABG: clinical outcome, patient satisfaction and mid-term RA graft patency. Journal of Cardiac Surgery. Published online May 7, 2020.

2. Gaudino M, Benedetto U, Fremes S, et al. Radial-Artery or Saphenous-Vein Grafts in Coronary-Artery Bypass Surgery. N Engl J Med. 2018;378(22):2069-2077. doi:10.1056/NEJMoa1716026

3. Tatoulis J, Buxton BF, Fuller JA, et al. Long-term patency of 1108 radial arterialcoronary angiograms over 10 years. Ann Thorac Surg. 2009;88(1):23-29; discussion 29-30. doi:10.1016/j.athoracsur.2009.03.086

4. Patel AN, Henry AC, Hunnicutt C, Cockerham CA, Willey B, Urschel HC. Endoscopic radial artery harvesting is better than the open technique. The Annals of Thoracic Surgery. 2004;78(1):149-153. doi:10.1016/j.athoracsur.2004.03.001

5. Bisleri G, Giroletti L, Hrapkowicz T, et al. Five-Year Clinical Outcome of Endoscopic Versus Open Radial Artery Harvesting: A Propensity Score Analysis. The Annals of Thoracic Surgery. 2016;102(4):1253-1259. doi:10.1016/j.athoracsur.2016.04.006

6. Navia JL, Brozzi N, Chiu J, et al. Endoscopic versus open radial artery harvesting for coronary artery bypass grafting. J Cardiovasc Surg (Torino). 2012;53(2):257-263.

7. Desai ND, Naylor CD, Kiss A, et al. Impact of Patient and Target-Vessel Characteristics on Arterial and Venous Bypass Graft Patency: Insight From a Randomized Trial. Circulation. 2007;115(6):684-691. doi:10.1161/CIRCULATIONAHA.105.567495

8. Gaudino MF, Lorusso R, Ohmes LB, et al. Open radial artery harvesting better preserves endothelial function compared to the endoscopic approach. Interactive

This article is protected by copyright. All rights reserved. 
CardioVascular and Thoracic Surgery. 2019;29(4):561-567.

doi:10.1093/icvts/ivz129

9. Lopes RD, Hafley GE, Allen KB, et al. Endoscopic versus open vein-graft harvesting in coronary-artery bypass surgery. $N$ Engl J Med. 2009;361(3):235-244. doi:10.1056/NEJMoa0900708

10. Zenati MA, Shroyer AL, Collins JF, et al. Impact of endoscopic versus open saphenous vein harvest technique on late coronary artery bypass grafting patient outcomes in the ROOBY (Randomized On/Off Bypass) Trial. $J$ Thorac Cardiovasc Surg. 2011;141(2):338-344. doi:10.1016/j.jtcvs.2010.10.004

11. Aldea GS, Bakaeen FG, Pal J, et al. The Society of Thoracic Surgeons Clinical Practice Guidelines on Arterial Conduits for Coronary Artery Bypass Grafting. Ann Thorac Surg. 2016;101(2):801-809. doi:10.1016/j.athoracsur.2015.09.100

12. Deb S, Cohen EA, Singh SK, et al. Radial artery and saphenous vein patency more than 5 years after coronary artery bypass surgery: results from RAPS (Radial Artery Patency Study). J Am Coll Cardiol. 2012;60(1):28-35. doi:10.1016/j.jacc.2012.03.037

13. Collins P, Webb CM, Chong CF, Moat NE, Radial Artery Versus Saphenous Vein Patency (RSVP) Trial Investigators. Radial artery versus saphenous vein patency randomized trial: five-year angiographic follow-up. Circulation. 2008;117(22):28592864. doi:10.1161/CIRCULATIONAHA.107.736215

14. Hayward PAR, Gordon IR, Hare DL, et al. Comparable patencies of the radial artery and right internal thoracic artery or saphenous vein beyond 5 years: results from the Radial Artery Patency and Clinical Outcomes trial. J Thorac Cardiovasc Surg. 2010;139(1):60-65; discussion 65-67. doi:10.1016/j.jtcvs.2009.09.043

15. Bleiziffer S, Hettich I, Eisenhauer B, et al. Patency rates of endoscopically harvested radial arteries one year after coronary artery bypass grafting. $J$ Thorac Cardiovasc Surg. 2007;134(3):649-656. doi:10.1016/j.jtcvs.2007.04.008

16. Burns DJP, Swinamer SA, Fox SA, et al. Long-term Patency of Endoscopically Harvested Radial Arteries: From a Randomized Controlled Trial. Innovations (Phila). 2015;10(2):77-84. doi:10.1097/imi.0000000000000133

17. Greene MA, Malias MA. Arm complications after radial artery procurement for coronary bypass operation. Ann Thorac Surg. 2001;72(1):126-128. doi:10.1016/s0003-4975(01)02680-7

18. Siminelakis S, Karfis E, Anagnostopoulos C, Toumpoulis I, Katsaraki A, Drossos G. Harvesting radial artery and neurologic complications. J Card Surg. 2004;19(6):505510. doi:10.1111/j.0886-0440.2004.04090.x

This article is protected by copyright. All rights reserved. 
19. Dick F, Hristic A, Roost-Krähenbühl E, et al. Persistent sensitivity disorders at the radial artery and saphenous vein graft harvest sites: a neglected side effect of coronary artery bypass grafting procedures. Eur J Cardiothorac Surg. 2011;40(1):221-226. doi:10.1016/j.ejcts.2010.11.020

20. Reyes AT, Frame R, Brodman RF. Technique for harvesting the radial artery as a coronary artery bypass graft. The Annals of Thoracic Surgery. 1995;59(1):118-126. doi:10.1016/0003-4975(94)00673-U

21. Simek M, Marcian P, Gwozdziewicz M, Ivo F, Tobbia P, Lonsky V. Endoscopic radial artery harvesting for coronary artery bypass grafting. A single center evolving experience. Biomed Pap Med Fac Univ Palacky Olomouc Czech Repub. 2013;157(1):64-69. doi:10.5507/bp.2012.032

22. Shapira OM, Eskenazi B, Murphy R, et al. Endoscopic radial artery harvest for coronary artery bypass grafting: initial clinical experience. Heart Surg Forum. 2004;7(5):E411-415. doi:10.1532/HSF98.20041049

23. Holman WL. Consequences of Radial Artery Harvest: Results of a Prospective, Randomized, Multicenter Trial. JAMA Surg. Published online September 25, 2013. doi:10.1001/jamasurg.2013.3721

24. Ikizler M, Ozkan S, Dernek S, et al. Does radial artery harvesting for coronary revascularization cause neurological injury in the forearm and hand? European Journal of Cardio-Thoracic Surgery. 2005;28(3):420-424. doi:10.1016/j.ejcts.2005.06.004

25. Bleiziffer S, Hettich I, Eisenhauer B, et al. Neurologic sequelae of the donor arm after endoscopic versus conventional radial artery harvesting. The Journal of Thoracic and Cardiovascular Surgery. 2008;136(3):681-687. doi:10.1016/j.jtcvs.2008.02.067

This article is protected by copyright. All rights reserved. 


\section{University Library}

\section{- M M I N E R VA A gateway to Melbourne's research publications}

Minerva Access is the Institutional Repository of The University of Melbourne

Author/s:

Robinson, NB;Tatoulis, J;Gaudino, M

Title:

Is endoscopic radial artery harvesting open for business?

Date:

2020-09-01

Citation:

Robinson, N. B., Tatoulis, J. \& Gaudino, M. (2020). Is endoscopic radial artery harvesting open for business?. JOURNAL OF CARDIAC SURGERY, 35 (9), pp.2155-2157. https:// doi.org/10.1111/jocs. 14708 .

Persistent Link:

http://hdl.handle.net/11343/276178 